\title{
MARIA JACINTHA: DRAMATURGIA DE AUTORIA FEMININA - HISTÓRIA DE UMA PESQUISA (")
}

\section{Marise Rodrigues \\ Doutoranda em Literatura Comparada, Universidade Federal Fluminense}

[...] sempre optei por plantar onde não há. E além disso sou fluminense, de nascimento e de raízes e confesso certa humilhação quando vejo que todas as capitais e grandes cidades do Brasil e, mesmo, pequenas cidades, têm seu teatro próprio [...]. Na atuação de toda a minha vida literária e artística, no Rio de Janeiro, sempre sonhei em poder, um dia, dar um bom Teatro a Niterói. Mas não deu mesmo. (JACINTHA, /s.n.t./).

Maria Jacintha Trovão da Costa Campos, professora, escritora, dramaturga, crítica, ensaísta, jornalista, tradutora e diretora teatral, nasceu no município de Cantagalo, Estado do Rio de Janeiro, em 25 de setembro de 1906, filha do desembargador Horácio José Campos e da professora Ana Lopes Trovão da Costa Campos, e faleceu em 20 dezembro de 1994, na cidade de Niterói. Sua trajetória se inicia como professora, atuando nos vários segmentos do ensino público, principalmente como professora de francês do Liceu Nilo Peçanha de Niterói. Ainda no magistério, atuou na Escola de Teatro Martins Pena, de onde foi requisitada, pela Divisão de Patrimônio Histórico e Artístico do Estado da Guanabara, para coordenar, documentar e historiar as atividades teatrais ligadas ao Rio de Janeiro,

\footnotetext{
Esse texto é um recorte do anteprojeto - Maria Jacintha: dramaturgia de autoria feminina entre cenas de interdição e reparação - história de uma pesquisa, apresentado à Coordenação de Pós-Graduação em Letras e aprovado para o ingresso no Doutorado de Literatura Comparada da Universidade Federal Fluminense, em dezembro de 2000, sob a orientação da Profa. Doutora Lúcia Helena Vianna. O estudo em questão tem como principal objetivo trazer à cena a obra da dramaturga Maria Jacintha, considerando os estudos específicos sobre a autoria feminina na dramaturgia brasileira a partir dos anos 30.
} 
função que exerceu até 1964, quando foi involuntariamente afastada pela ditadura militar. Suportou os vários momentos de censura no Brasil, com suas peças proibidas aqui e em Portugal.

No jornalismo, fundou e dirigiu com Silvia de Léon Chalréo e Áureo Ottoni de Mendonça Lima a revista Esfera, onde escrevia sobre crítica teatral; colaborou em diversos jornais e revistas como: Correio da Manhã, O Jornal, O Globo, O Homem Livre, Revista Francesa do Brasil, Jornal do Comércio, Flama, Vida, Leitura, O Mundo, entre outros. Na esfera teatral, Maria Jacintha fundou e dirigiu, com Dulcina de Morais, Odilon Azevedo e Oswaldo Mota, o Teatro de Arte do Rio de Janeiro, lançando nomes como Nicete Bruno, Felipe Wagner, Fernanda Montenegro, Kléber Mendonça, Isac Bardavid, Mauro Mendonça, Jorge Cherques, entre outros. Também fundou e dirigiu o Teatro Fluminense de Arte, com temporadas no Teatro Municipal de Niterói e no Cassino Icaraí, assim como o Teatro Estável de Niterói, em 1978. Em alguns momentos, também esteve à frente do Teatro do Estudante do Brasil.

Como dramaturga, Maria Jacintha estréia, em 1937, com a peça $O$ gosto da vida, que, segundo a crítica da época, apresenta um trabalho de "grande audácia intelectual", discutindo "questões novas" e revelando "as esplêndidas qualidades de uma escritora para o difícil gênero do teatro". Mesmo recebendo críticas favoráveis, a peça foi censurada e retirada de cartaz por ter sido considerada atentatória à moral e aos bons costumes, por falar do "amor em liberdade, da dissolução dos elos da família, da licenciosidade amorosa," coisa pouco tolerada pela igreja e por algumas "mentalidades da política integralista" da época. Tal episódio, no entanto, não impediu que a peça recebesse o $1^{\circ}$ prêmio de Teatro de 1938, da Academia Brasileira de Letras. Maria Jacintha também recebeu outros reconhecimentos que se seguiram na sua carreira de escritora, como a Medalha Machado de Assis pela tradução da peça As três irmãs, de Anton Tchekov, do Serviço Nacional de Teatro em 1953, e a Medalha Machado de Assis pelo conjunto de sua obra, concedida pela Academia Brasileira de Letras em 1959. Maria Jacintha também pertenceu à Academia de Letras do Estado do Rio de Janeiro, tendo como patrona a também escritora e dramaturga Júlia Lopes de Almeida. Integrou o Conselho de Teatro do Museu da Imagem e do Som e o Conselho Municipal de Cultura de Niterói. Recebeu a Ordem do Mérito de Araribóia, da Prefeitura de Niterói, em 1978. 
Em relação a sua obra dramatúrgica, destacamos as seguintes peças: $O$ gosto da vida (inédita), encenada pela Companhia Jaime Costa em 1937; A doutora Magda (inédita), encenada pela Companhia Iracema Alencar e Álvaro Pires em 1938; Conflito, encenada pela Companhia Dulcina e Odilon em 1939 e publicada pela Editora Tucano de Porto Alegre em 1942 ; Convite à vida, encenada pela Companhia Dulcina e Odilon em 1945 e publicada pela Editora Fon Fon e Seleta do Rio de Janeiro em 1969 ; Já é manhã no mar, encenada pelo Teatro de Arte do Rio de Janeiro em 1947 e publicada pela Editora Vozes de Petrópolis em 1968; "Um não sei quê que nasce não sei onde", peça cujo título homenageia Camões, publicada pela Editora Fon - Fon e Seleta em 1968; Intermezzo da imortal esperança, publicada pelo Serviço Nacional de Teatro em 1973, entre outros textos ainda inéditos. Na dramaturgia para o radioteatro registram-se as peças $O$ vampiro, Travessia, Uma estória para uma canção, $O$ gosto da vida, A confidente e Conflito, apresentadas pela Rádio Nacional, com adaptações de Janete Clair, Dias Gomes, Hélio do Soveral e Cahuê Filho. Além desses títulos, encontra-se vasta produção de crítica teatral, de estudos literários, de narrativa de ficção, ainda inéditos, assim como traduções e adaptações para o teatro. Destacam-se, entre estas, Anfitrião 38, de Jean Giraudaux, Jezabel, de Jean Anouilh, A filha de Iorio, de Dannunzio, As três irmãs, de Anton Tchekov, Dias felizes, de Claude-André Puget e Nunca me deixarás e Tessa, de Magareth Kennedy.

De início, duas constatações foram importantes para direcionar os rumos dessa pesquisa sobre a dramaturgia jacinthiana. A primeira veio da crítica de teatro Luiza Barreto Leite, que, refletindo sobre a presença das mulheres no teatro brasileiro, alude sobre a importância de Maria Jacintha:

Mas aqui é preciso que se abram alas para uma nova personalidade das mais importantes e, talvez, aquela a quem nossos críticos, ensaístas e historiadores mais devem uma reparação: Maria Jacintha, autora, diretora e professora de teatro, cujo lugar como organizadora de movimentos de arte nunca ficou bem definido, devido a seu estranho retraimento (não digo modéstia porque este é um sentimento inconsciente e o retraimento da grande figura humana a quem Galante 
de Sousa dedica apenas uma frase: 'Jacinta, Maria. Nome literário da autora teatral Maria Jacinta Trovão da Costa Campos', é conseqüente de uma forte consciência). (...) Seus feitos estão aí, ligados a muita gente vitoriosa, seu nome vai sumindo no mistério daquelas que amaram o teatro mais do que suas próprias carreiras [sem grifo no original] (LEITE,1965, p.25-26).

A segunda constatação é de Elza Cunha de Vincenzo, que verifica a ausência da mulher no espaço do teatro como autora e que registra a presença de Maria Jacintha na dramaturgia brasileira anterior à década de 60 . Fato relevante, mas as informações fornecidas pela pesquisadora, na breve síntese sobre a dramaturga, são imprecisas, necessitando de retificação. Hoje, a partir da leitura de seus documentos e textos inéditos, já podemos traçar um perfil diferente daquele feito pela pesquisadora. Dentre as informações, a pesquisadora atribui à peça Conflito o prêmio da Academia Brasileira de Letras, mas a peça premiada foi $O$ gosto da vida, texto inaugural e ainda inédito. Também registra a peça Já é manhã no mar, encenada em 1947, como sendo a última peça da escritora, quando sabemos que, até o momento, há inúmeros textos inéditos e a última peça editada foi Intermezzo da imortal esperança, de 1973.

Constatando essas imprecisões, direcionei-me para investigar a vida e a obra de Maria Jacintha, buscando revelar uma parte que a historiografia teatral ainda não registrou completamente, a produção dramatúrgica de autoria feminina brasileira, ao mesmo tempo, promovendo a "reparação" crítica tão devida à Maria Jacintha, conforme sugeriu Luiza Barreto Leite.

A pesquisa em questão teve o seu início, ou pelo menos a sua semente, num encontro casual. Isso aconteceu em dezembro de 1995, no Instituto de Letras da UFF, quando participei de uma conversa informal entre a coordenadora do Espaço Cultural Maria Jacintha, Profa Maria Jacintha Sauerbronn de Melo, herdeira da dramaturga, e o professor Jorge de Sá, especialista e pesquisador de literatura e dramaturgia brasileiras. Nesse encontro, a herdeira buscava o apoio da UFF para receber o acervo e divulgar a obra da escritora fluminense, ainda desconhecida dos meios literários e acadêmicos. 
Nesse sentido, interessei-me em conhecer a obra da escritora, retomando, assim, antigos estudos sobre gêneros e o interesse de levantar a produção cultural de Niterói, especialmente a produção relativa às escritoras fluminenses. Resgatando sonhos antigos, passo a me envolver com a pesquisa, orientada e incentivada, naquele momento, pelo Prof Dr. Jorge de Sá, a quem, saudosamente, credito o início desse trabalho.

Os princípios que orientam a pesquisa em questão estão ligados aos estudos sobre o resgate de obras de escritoras, principalmente das dramaturgas brasileiras. A pesquisa sobre Maria Jacintha busca revelar um corpus significativo da produção desconhecida de escritoras do passado, tornadas invisíveis pela mediação crítica, quase exclusivamente masculina, a partir de uma postura revisionista, que dê um novo olhar sobre esses textos.

Desde então tem-se evidenciado uma preocupação consensual com a revisão da historiografia literária, chamada de crítica arqueológica, revelando algo que está oculto, subterrâneo, ou melhor, silenciado. É importante ressaltar que esse trabalho de resgate da cultura realizada por mulheres delineia um novo mapa para os estudos da literatura em geral, assim como revela que os novos objetos culturais não cabem nas lacunas da historiografia oficial, necessitando, portanto, de novos paradigmas que descrevam satisfatoriamente os protocolos literários das mulheres-escritoras, conforme explicita Constância Duarte:

[...] estamos trabalhando na reconstrução e na crítica de modelos, de modo a tornar compreensível e instigadora a perspectiva feminina. Estamos naturalmente contribuindo para a revisão dos valores normativos do cânone literário, ao apresentarmos a todo instante novas escritoras e novas obras, em tudo merecedoras de aí serem incluídas. Também, tornouse uma questão política de grande premência verificar como a raça, o gênero, a classe e as preferências sexuais interagem (BRANDÃO, 2000, p.21).

Outra lacuna a ser preenchida pela crítica especializada é a do resgate da produção dramatúrgica brasileira, para que se possa 
escrever uma História do Teatro Brasileiro, conforme depoimento do crítico teatral Sábato Magaldi:

Ainda está por escrever-se uma História do teatro brasileiro. Somente quando se fizer um levantamento completo de textos se poderá realizar um estudo satisfatório de todos os aspectos da vida cênica dramaturgia, evolução do espetáculo, relações com as demais artes e com a realidade social do país, existência do autor, do intérprete e dos outros componentes da montagem, presença da crítica e do público. Por enquanto, mesmo que seja imensa a boa vontade, se esbarrará em obstáculos intransponíveis. Talvez a tarefa não seja de um único pesquisador: exige busca paciente em arquivos e jornais, leitura de alfarrábios e inéditos, a esperança de que se publiquem documentos inencontráveis. Todos fornecemos subsídios para a obra que - acreditemos um dia virá a lume (MAGALDI, 1997, p.289).

Essas lacunas têm sido preenchidas, mesmo que de maneira ainda incompleta, pois sabemos como é difícil e precária a pesquisa na área da dramaturgia, justamente pela falta de registro das informações biobibliográficas, as quais servem de base para qualquer pesquisa mais específica. Nesse sentido, vemos com satisfação os trabalhos editados pelos Cadernos de Pesquisa em Teatro, cuja série Bibliografia apresenta as pesquisas: Teatro brasileiro no século $X X$, pesquisa coordenada pela Profa Tânia Brandão, que apresenta os títulos de teatro brasileiro existentes nas Bibliotecas do Centro de Letras e Artes da Uni-Rio e da Fundação Nacional de Arte; Vida de artista, pesquisa coordenada pela Profa. Maria Helena Werneck, que apresenta biografia anotada de obras biográficas de autores, atores, cenógrafos e empresários do teatro brasileiro e ainda oferece dois artigos: História do teatro, história no feminino e Procópio, personagem de si mesmo. E $O$ edifício teatral através da crônica: os gêneros dramáticos, a cenografia, a dança e a cena lírica integrando a arquitetura, pesquisa coordenada pela profa Evelyn Furquim Werneck Lima, que apresenta bibliografia anotada e comentada de periódicos e obras sobre arquitetura, história da cultura, gêneros dramáticos, cenografia, dança e cena lírica. 
Contamos, ainda, com as pesquisas Cem anos de Teatro em São Paulo, de Sábato Magaldi e Maria Thereza Vargas, e Dulcina e o teatro de seu tempo, de Sérgio Viotti, ambas editadas recentemente.

Há que se registrar também a criação do GT de Dramaturgia e Teatro da ANPOLL, que tem como principais linhas de pesquisa a dramaturgia comparada, a crítica do texto dramático e/ou do teatro, a história do teatro e a teoria do teatro. Tais estudos têm como objetivos pesquisar a literatura dramática e suas relações com a intersemioticidade, a interdisciplinaridade, a intertextualidade e a interculturalidade, contribuindo para a sistematização e a produção de conhecimento sobre a Literatura Dramática e Teatro em nosso país. O GT editou a primeira amostra dessas pesquisas em sua Revista Dramaturgia \& Teatro, apresentada no XV Encontro Nacional da ANPOLL, em outubro de 2000, na UFF, em Niterói, Rio de Janeiro.

Em trabalho semelhante, privilegiando o resgate da vida e das obras das mulheres-escritoras, contamos com as publicações do Índice de dramaturgas brasileiras do século XIX, 1996, extensa pesquisa

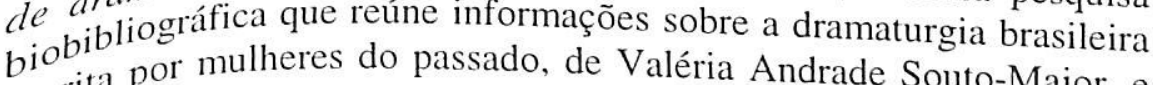
$e^{s^{c} \text { rita }}$ por mulogia de Escritoras Brasileiras Valéria Andrade Souto-Maior, e da antologia de Escritoras Brasileiras do século XIX,1999, trabalho de pesquisa, organizado por Zahidé Lupinacci Muzart, que registra, entre outras escritoras, as dramaturgas Maria Angélica Ribeiro e Josefina Álvares de Azevedo, pela importância que elas representam na história da dramaturgia brasileira. De igual valor o Dicionário Mulheres do Brasil - de 1500 até a atualidade, organizado por Schuma Shumaher e Érico Vital Brasil. Há ainda os estudos A tradição obscura: o teatro feminino no Brasil, 2000, de Maria Cristina de Souza, e O florete e a máscara: Josephina Álvares de Azevedo, dramaturga do séculoXIX, 2001, de Valéria Souto-Maior, ambos direcionados para a história e o resgate da dramaturgia feminina.

Os estudos sobre a dramaturgia brasileira ainda suscitam percursos lacunares, principalmente no âmbito da preservação e edição de textos teatrais: [...] encontram-se obstáculos tanto para estabelecer datas de encenação e criação dos textos como para conhecê-los e lê-los, já que as peças editadas são em pequeno número e muitas ediçôes se acham esgotadas (SOUZA, 2001, p.16). Nesse sentido, por exemplo, tem sido relevante o trabalho de reedição das obras de Nélson Rodrigues, assim como, recentemente, a edição do 
teatro de Plínio Marcos e de Hilda Hilst, até então inéditos. Mas, quanto à dramaturgia de autoria feminina, ainda é necessário um mapeamento mais preciso e a edição dos textos inacessíveis e dos inéditos.

A principal fonte de pesquisa sobre a dramaturgia de Maria Jacintha tem sido os documentos da escritora que foram doados ao Arquivo-Museu de Literatura Brasileira da Fundação Casa de Rui Barbosa, no Rio de Janeiro, e que estão sendo organizados para a elaboração do Inventário do Arquivo Maria Jacintha, sob a orientação da Profa Dra Eliane Vasconcellos, especialista em Literatura Brasileira e responsável pelo trabalho de pesquisa e arquivos naquela fundação.

Numa outra vertente, foi lançado, recentemente, o Catálogo Coleção Maria Jacintha: dramaturgia \& teatro, que registra os títulos referentes à bibliografia de teatro e de dramaturgia em geral, que compõem a Biblioteca Referencial de Teatro de Maria Jacintha, doada à Universidade Federal Fluminense, em 15 de dezembro de 1999, pelo Espaço Cultural Maria Jacintha, para ser incorporada ao acervo da Biblioteca Central do Gragoatá, através do Núcleo de Documentação dessa Universidade. Esse catálogo faz parte da pesquisa iniciada em 1996, quando se começou a organizar o acervo da dramaturga fluminense com a colaboração dos estagiários do Curso de Arquivologia da UFF.

Para a elaboração desse catálogo foram selecionados os títulos, seguindo um critério tipológico que se organiza nas séries livros, periódicos e folhetos. Cada série foi catalogada seguindo a ordem alfabética, apresentando os dados referenciais de cada verbete, respeitando-se a grafia original. Na série livros foram agrupadas as obras de autores nacionais e estrangeiros, totalizando 474 verbetes; entre eles, destacam-se, cronologicamente, as obras: Theatro do Doutor Joaquim Manoel de Macedo, tomo I e II, editada por H. Garnier, no Rio de Janeiro, em 1863 e Les origines du théâtre antique et du théâtre moderne ou histoire du génie dramatique, de Charles M. Magnim, editada por Auguste Eudes, em Paris, em 1868.

Nessa série, também merece relevância a dramaturgia de Maria Jacintha, que apresenta as seguintes peças: Conflito - 1942, Já é manhã no mar - 1968, Um não sei quê que nasce não sei onde 1968. Convite à vida - 1969 e Intermezzo da imortal esperança - 
1973, reafirmando a presença da escritora na dramaturgia brasileira, inaugurada, possivelmente, por Maria Angélica Ribeiro. Da mesma forma, a presença das obras traduzidas e adaptadas por Maria Jacintha, como: Os trabalhadores do mar - 1973, de Victor Hugo; O diabo e o bom Deus - 1970, de Jean Paul Sartre; A estação atômica - 1966, de Halldor Laxness; O sapato de cetim - 1970, peça em duas partes e vários quadros, de Paul Claudel e As três irmãs, drama em 4 atos, de Anton Pavlovitch Tchékhov, tradução individual na edição de 1976 e com Boris Schnaiderman nas edições de 1979 e 1982 para a editora Abril Cultural, em São Paulo.

$\mathrm{Na}$ série periódicos encontram-se as principais revistas nacionais e estrangeiras sobre dramaturgia e teatro, totalizando 59 verbetes. Dentre os periódicos nacionais, destacam-se Esfera Revista de Letras, Artes e Ciências, editada no Rio de Janeiro, em 1938 e dirigida por Maria Jacintha até 1940, e Fon-Fon - Revista Semanal Ilustrada, editada no Rio de Janeiro, em 1937, entre outras. Dos periódicos estrangeiros, verifica-se maior relevância para os títulos em francês e, dentre eles, destaca-se, cronologicamente, a revista L'Illustration, datada de 1901 .

Já na série folhetos há o registro dos principais eventos teatrais, acontecidos em Niterói e na cidade do Rio de Janeiro, e aos quais, certamente, a dramaturga assistiu. Essa série é composta de 164 verbetes que foram descritos de forma a fornecer as indicações mais precisas possíveis, embora em muitos momentos tais documentos não fornecessem as informações necessárias. Destaca-se, cronologicamente, nessa série, o folheto La traviata, ópera apresentada pela Grande Cia. Lírica de Verdi, no Rio de Janeiro, em 1937. Assim, com as três séries registradas, propicia-se aos pesquisadores e ao público leitor, em geral, o acesso a fontes imprescindíveis aos estudos de literatura, dramaturgia, teatro e afins.

Ainda com a preocupação de resgatar as obras ainda inéditas da dramaturga, há também uma possível edição da peça $O$ gosto da vida, texto inaugural da escritora fluminense na dramaturgia brasileira, datado de 1937. A possível edição desse texto faz parte dos objetivos desta pesquisa e constará como parte integrante da tese em questão. Numa outra margem, pretende-se ampliar a pesquisa pelos principais arquivos, bibliotecas e teatros, situados no Estado do Rio de Janeiro e nas capitais por onde as peças de Maria Jacintha foram encenadas, e 
também completar a série de entrevistas sobre a dramaturga e sua obra.

Finalmente, ao dar visibilidade ao texto teatral de Maria Jacintha, que foi contemporânea do teatro de Oswald de Andrade, com a peça $O$ rei da vela, de 1937, e do de Nélson Rodrigues, com a peça Vestido de Noiva, de 1943, estar-se-á legitimando o estudo da dramaturgia de autoria feminina, gênero ainda pouco contemplado na historiografia teatral brasileira.

\section{Referências Bibliográficas}

BRANDÃO, Izabel(org.). Boletim do GT A Mulher na LiteraturaANPOLL. Maceió: UFAL, v.8, 2000.

CADERNOS de pesquisa em teatro. O edifício teatral através da crônica: os gêneros dramáticos, a cenografia, a dança e a cena lírica integrando a arquitetura Rio de Janeiro: Uni-Rio/Escola de Teatro, v.4, 1997 (Série bibliografia).

CADERNOS de pesquisa em teatro. Teatro brasileiro no século XX. Rio de Janeiro: Uni-Rio/Escola de Teatro, v.1, 1996 (Série bibliografia).

CADERNOS de pesquisa em teatro. Vida de artista. Rio de Janeiro: Uni-Rio/Escola de Teatro, v.2, 1996 (Série Bibliografia).

DICIONÁRIO Mulheres do Brasil: de 1500 até a atualidade. Rio de Janeiro: Jorge Zahar, 2000.

LEITE, Luiza Barreto. A mulher no teatro brasileiro. Rio de Janeiro: Espetáculo, 1965.

MAGALDI, Sábato. Panorama do teatro brasileiro. São Paulo: Global, 1997.

MAGALDI, Sábato \& VARGAS, Maria Thereza. Cem anos de teatro em São Paulo (1875- 1974). São Paulo: Editora Senac São Paulo, 2000.

MUZART, Zahidé Lupinacci (org.). Escritoras brasileiras do século $X I X$. Florianópolis: Editora Mulheres ; Santa Cruz do Sul: EDUNISC, 1999. 
RODRIGUES, Marise (org.). Catálogo - Coleção Maria Jacintha: dramaturgia \& teatro. Niterói: Bacantes Edição \& Arte, 2001.

RODRIGUES, Marise. O acervo de Maria Jacintha: uma pesquisa em processo. Revista Dramaturgia \& Teatro, Niterói, p.161-167. 2000.

RODRIGUES, Marise. O acervo literário de Maria Jacintha, escritora e dramaturga fluminense. In: Seminário Nacional Mulher e Literatura, 7, 1997, Niterói. Anais... Niterói: EdUFF,1999. p.290-294.

RODRIGUES, Marise. Pesquisa-projeto sobre o acervo de Maria Jacintha. In: Seminário sobre museus-casas, 2.1996, Rio de Janeiro. Anais... Rio de Janeiro. Fundação Casa de Rui Barbosa,1998. p.170-171.

RODRIGUES, Marise. Uma pesquisa-projeto sobre o acervo de Maria Jacintha, escritora e teatróloga fluminense. Caderno Seminal, Rio de Janeiro, 4, p.83-88. 1997.

RODRIGUES, Marise. Teatro: leitura em cena - O gosto da vida, de Maria Jacintha. Caderno dos resumos das comunicações- $12^{\circ}$ Congresso de Leitura do Brasil/COLE, Campinas, UNICAMP, p.220, 1999.

SOUTO-MAIOR, Valéria Andrade. Índice de dramaturgas brasileiras do século XIX. Florianópolis: Editora Mulheres,1996.

SOUTO-MAIOR, Valéria Andrade. O florete e a máscara: Josephina Álvares de Azevedo, dramaturga do século XIX. Florianópolis: Editora Mulheres, 2001.

SOUZA, Maria Cristina de. A tradição obscura: o teatro feminino no Brasil. Niterói: Bacantes Edição \& Arte, 2001.

VINCENZO, Elza Cunha de. Um teatro da mulher: dramaturgia feminina no palco brasileiro contemporâneo. São Paulo: Perspectiva, 1992.

VIOTTI, Sérgio. Dulcina e o teatro de seu tempo. Rio de Janeiro: Lacerda Ed., 2000. 